\title{
FIBROMA DE CÉLULAS GIGANTES: CONSIDERAÇÕES GERAIS E RELATO DE CASO
}

\author{
GIANT CELL FIBROMA: GENERAL CONSIDERATIONS AND CASE REPORT
}

\author{
Elen de Souza Tolentino* \\ Bruna Stuchi Centurion " \\ José Humberto Damante
}

\begin{abstract}
RESUMO
O fibroma de células gigantes apresenta-se como um nódulo séssil ou pediculado, assintomático e geralmente menor que $1 \mathrm{~cm}$ de diâmetro. A maioria dos casos é diagnosticada em pessoas com idade entre $10 \mathrm{e}$ 30 anos. A localização mais comum é na gengiva inferior, seguida da gengiva superior, língua e palato. $\mathrm{O}$ diagnóstico diferencial inclui papiloma, fibroma, granuloma piogênico e lesão periférica de células gigantes. Microscopicamente, o FCG é uma massa náo encapsulada de tecido conjuntivo fibroso que contém numerosos fibroblastos, alguns destes multinucleados. Essas células são facilmente observadas na periferia da lesão, enquanto as áreas centrais apresentam fibroblastos típicos. A superfície epitelial é frequentemente corrugada e atrófica. O tratamento é constituído de remoção cirúrgica conservadora, uma vez que a recorrência é rara. O objetivo deste trabalho é apresentar um caso de extenso fibroma de células gigantes em gengiva superior de um homem de 40 anos que foi diagnosticado após biópsia exisional e exame microscópico.
\end{abstract}

DESCRITORES: Fibroma • Células gigantes $\bullet$ Mucosa bucal

\section{ABSTRACT}

Giant cell fibroma appears as an asymptomatic sessile or pedunculated nodule that is smaller than $1 \mathrm{~cm}$ in diameter. Most cases are diagnosed in persons aged 10-30 years. The most common sites are the mandibular gingiva, followed by the maxillary gingiva, the tongue, and the palate. The clinical differential diagnosis includes squamous papilloma, irritation fibroma, pyogenic granuloma, and peripheral giant cell granuloma. Microscopically, a giant cell fibroma is an unencapsulated mass of fibrous connective tissue that contains numerous characteristic large, plump, spindle-shaped and stellate fibroblasts, some of which are multinucleated. These cells are easily observed in the peripheral areas of the lesion, while the more central areas contain typical fusiform fibroblasts. The surface epithelium is often corrugated and atrophic. Conservative excisional biopsy is curative, and its findings are diagnostic. Recurrence is rare. The aim of this work is to present a case of a big giant cell fibroma in the upper gingival in a 40-years-old man, whose was diagnosed after excisional biopsy and microscopic exam.

DESCRIPTORS: Fibroma • Giant cells • Mouth mucosa

\footnotetext{
* Mestre em Estomatologia pela Faculdade de Odontologia de Bauru da Universidade de São Paulo (FOB-USP) elen_tolentino@hotmail.com ** Mestranda em Estomatologia pela Faculdade de Odontologia de Bauru da Universidade de São Paulo (FOB-USP) bscenturion@hotmail.com *** Professor Titular do Departamento de Estomatologia da Faculdade de Odontologia de Bauru da Universidade de São Paulo (FOB-USP) damante@usp.br
} 
Tolentino ES, Centurion BS, Damante JH. Fibroma de células gigantes: considerações gerais e relato de caso. Revista de Odontologia da Universidade Cidade de São Paulo 2009 set-dez; 21(3): 277-81

\section{INTRODUÇÃO}

O fibroma de células gigantes (FCG) é considerado por alguns autores como uma lesão não neoplásica benigna, descrita inicialmente por Weathers e Callihan em 1974 (Campos e Gomes ${ }^{3}$ 1999, Odell et al. ${ }^{10} 1994$ ) representando um crescimento reativo focal da mucosa bucal (Miguell et al. ${ }^{6}$ 1999, Miguell et al. ${ }^{7}$ 1996). Essa lesão representa $5 \%$ de todas as proliferações fibrosas submetidas à biópsia (Neville et al. ${ }^{8}$ 1998).

Microscopicamente, o FCG exibe características peculiares, sendo composto por um tecido conjuntivo fibroso geralmente arranjado frouxamente, com ausência de inflamação e revestido por epitélio pavimentoso estratificado hiperplásico, sendo a presença de células gigantes mono, bi ou multinucleadas, fusiformes ou estreladas e localizadas predominantemente na lâmina própria papilar, a sua principal característica histopatológica (Albuquerque et al. ${ }^{1}$ 2001, Campos e Gomes ${ }^{3}$ 1999, Magnusson e Rasmusson ${ }^{4}$ 1995).

O FCG é tratado pela excisão cirúrgica conservadora, sendo as recidivas raras.

\section{RELATO DE CASO}

Paciente de 40 anos, melanoderma, gênero masculino, procurou a clínica de estomatologia da Faculdade de Odontologia de Bauru (FOB-USP) com queixa de "lesão em gengiva". Não apresentava nenhum problema sistêmico, não era fumante nem possuía antecedentes familiares ou histórico de trauma ou infecção na região.

Ao exame físico intrabucal, observou-se um nódulo séssil de coloração rósea com uma demarcação central mais avermelhada, assintomático, resiliente à palpação, de textura lisa e tempo de evoluçáo de aproximadamente 1 ano, localizado na gengiva, inserido próximo ao dente 11 e com $2 \mathrm{~cm}$ de diâmetro (Figura 1). Os dentes $11 \mathrm{e}$ 21 apresentavam restauraçóes cervicais antigas e com infiltração. A radiografia periapical da região não demonstrou nenhuma alteração.

Diante dos achados clínicos, nosso diagnóstico presuntivo foi de lesão periférica de células gigantes, fibroma ossificante periférico e fibroma.

O paciente foi submetido à biópsia excisional da lesão, sob anestesia local. A lesão foi removida juntamente com uma porção da gengiva inserida envolvida, fazendo com que o tecido ósseo na região ficasse exposto. Por esse motivo, foi colocado sobre essa área cimento cirúrgico, favorecendo a cicatrizaçáo por segunda intenção. Este material foi substituído após 7 dias e removido após
15. Nesse momento, o paciente já apresentava evolução favorável do quadro, com cicatrização satisfatória e ausência de qualquer sintomatologia. Em 3 meses, a área encontrava-se completamente cicatrizada (Figura 3).

O exame microscópico da peça removida revelou fragmento de mucosa bucal constituído por epitélio estratificado pavimentoso atrófico paraqueratinizado, com focos de alteração hidrópica e com papilas estreitas e alongadas. Subjacente, observou-se tecido conjuntivo frouxo contendo numerosos fibroblastos grandes e estrelados, sendo que alguns deles apresentavam-se multinucleados. Notou-se ainda a presença de vasos sanguíneos dilatados e congestos. De acordo com estas características, o diagnóstico definitivo foi de fibroma de células gigantes (Figura 4).

O paciente foi encaminhado para tratamento periodontal e restaurador.e encontra-se em proservação de 1 ano, sem qualquer sinal de recidiva.

\section{DISCUSSÃO}

O FCG, a hiperplasia fibrosa e o fibroma, constituem algumas das mais frequentes lesões fibrosas dos tecidos moles orais. Com o intuito de investigar a origem dessas células e se elas têm a mesma origem nas três entidades citadas, Miguel et al..$^{5}$ (2003) propuseram-se a realizar um estudo imuno-histoquímico utilizando dois marcadores celulares (vimentina e actina de músculo) comparando os achados nas lesóes estudadas. Diante dos resultados, verificaram que as células gigantes mono, bi ou multinucleadas estreladas, observadas nas lesões estudadas, expressaram predominantemente a vimentina, sugerindo uma possível natureza fibroblástica, sem, contudo, determinar tal origem. Além disso, não se evidenciou uma participação significativa de miofibroblastos na etiopatogenia dessas lesôes, baseando-se nos achados para o marcador HHF-35 (Miguel et al. ${ }^{5}$ 2003).

A hiperplasia fibrosa é considerada um crescimento reativo focal que aparece circundando as margens ou bordas de próteses totais ou parciais removíveis mal adaptadas, estando relacionada com a irritação crônica causada por elas e por forças oblíquas resultantes de desajustes oclusais (Pinto-Coelho et al. ${ }^{11}$ 2000). Microscopicamente, caracteriza-se por um epitélio pavimentoso estratificado frequentemente hiperplásico, ceratinizado, alternando áreas de hiperceratose e paraceratose. O tecido conjuntivo varia de acordo com o estágio de desenvolvimento da lesão, apresentando-se como um tecido de gramulação nas lesôes jovens e com um conjuntivo 


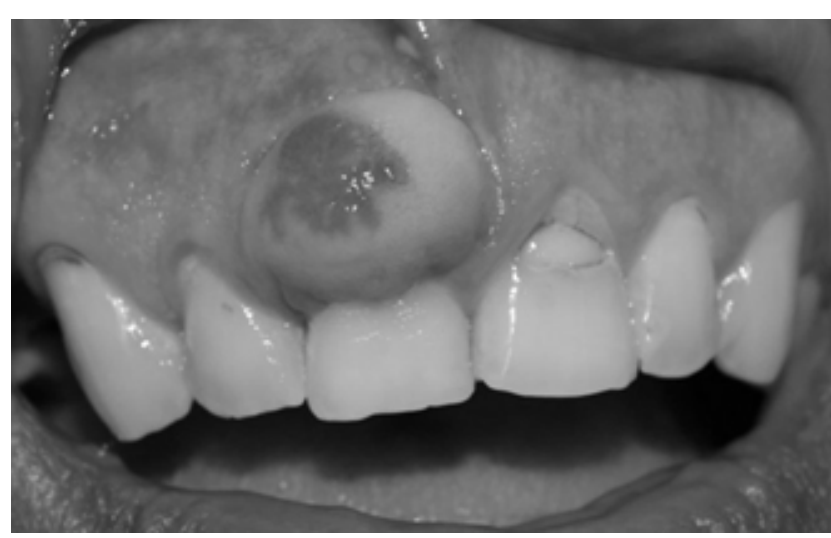

Figura 1 - Nódulo séssil em gengiva inserida próximo ao dente 11.

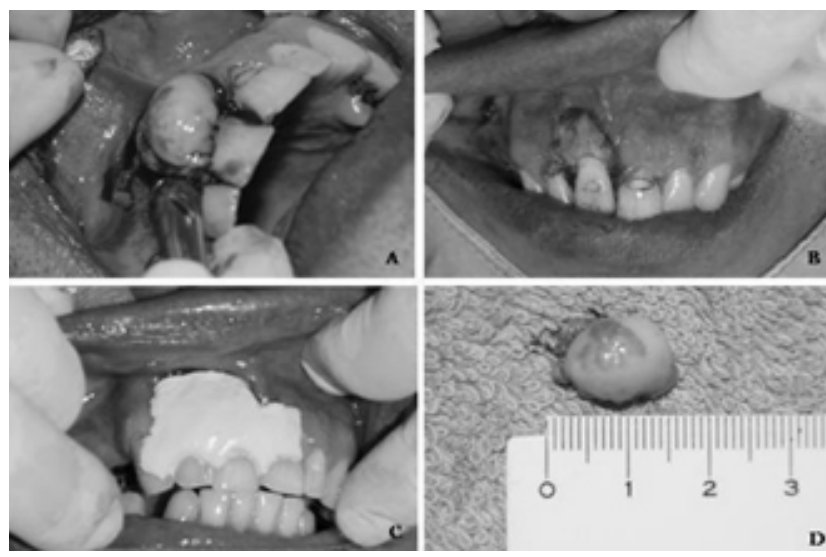

Figura 2 - A: Biópsia excisional da lesão; B: Remoção de gengiva inserida e exposiçáo do tecido ósseo subjacente; $\boldsymbol{C}$ : Colocação de cimento cirúrgico na região; D: Peça removida.

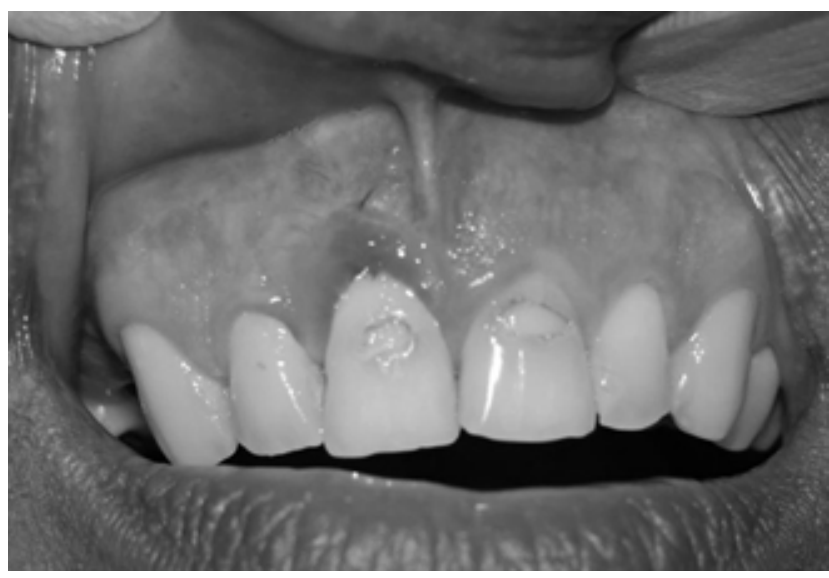

Figura 3 - Pós-operatório de 3 meses mostrando cicatrização favorável por segunda intenção.

denso e fibroso nas lesóes mais antigas, exibindo geralmente um infiltrado de células inflamatórias crônicas (Pinto-Coelho e Zucoloto ${ }^{12}$ 1998).
O fibroma representa um tumor de natureza conjuntiva originário de proliferação de fibroblastos (Araujo e Araujo ${ }^{2}$ 1994) sendo considerado por Shafer et al. ${ }^{14}$ (1987) a neoplasia de tecido mole mais comum da cavidade bucal. Porém Neville et al. ${ }^{8}$ (1998) afirmam que há dúvidas quanto a essa lesão representar um neoplasma verdadeiro; na maioria das situaçóes talvez seja uma hiperplasia reacional do tecido conjuntivo fibroso em resposta à irritação local ou a um trauma, apresentando-se como uma massa nodular de tecido conjuntivo denso e colagenizado, coberto por um epitélio pavimentoso estratificado, geralmente atrófico.

O FCG é observado em pacientes jovens (Magnusson e Rasmusson ${ }^{4}$ 1995), sendo mais frequente nas três primeiras décadas de vida, apresentando-se como lesões assintomáticas, papilíferas ou lobuladas, pediculadas, medindo menos que $1 \mathrm{~cm}$ de diâmetro, acometendo principalmente a gengiva inferior e o ápice e borda lateral da língua (Odell et al. ${ }^{10}$ 1994). Neville et al. ${ }^{8}$ (1998) afirmam ainda que há uma leve predileção pelo gênero feminino. Esses dados não corroboram o caso relatado neste trabalho, uma vez que o nódulo séssil apresentava $2 \mathrm{~cm}$ de diâmetro e localizava-se na gengiva superior de um paciente do gênero masculino de 40 anos de idade.

Microscopicamente, o FCG é uma massa não encapsulada de tecido conjuntivo fibroso que contém numerosos fibroblastos, alguns deles multinucleados. Essas células são facilmente observadas na periferia da lesão, enquanto que as áreas centrais apresentam fibroblastos típicos. A superfície epitelial é frequentemente corrugada e atrófica (Miguel et al. 2003 Nogueira et al. ${ }^{9} 2004$, Santiago et al. ${ }^{13}$ 2003) . Esses achados corroboram os dados por aqui encontrados.

Essas células gigantes mono, bi ou multinucleadas não são exclusivas do FCG, sendo detectadas também em outras lesôes fibrosas como fibroma ungueal, angiofibroma acral e fibroblastoma desmoplásico (Campos e Gomes $^{3}$ 1999) e mais especificamente nas hiperplasias fibrosas e fibromas da cavidade bucal. A natureza dessa população celular vem sendo amplamente discutida por diversos pesquisadores (Campos e Gomes ${ }^{3}$ 1999, Magnusson e Rasmusson ${ }^{4}$ 1995, Odell et al. ${ }^{10}$ 1994), porém ainda não foi completa mente estabelecida.

O diagnóstico diferencial do FCG inclui o papiloma escamoso, fibroma, granuloma piogênico e lesão periférica de células gigantes.

Por apresentar superfície lisa, base séssil e tamanho considerável, descartamos a hipótese de papiloma. $\mathrm{O}$ 
Tolentino ES, Centurion BS, Damante JH. Fibroma de células gigantes: considerações gerais e relato de caso. Revista de Odontologia da Universidade Cidade de São Paulo 2009 set-dez; 21(3): 277-81

granuloma piogênico também não foi considerado por tratar-se de uma lesão mais comum em mulheres e por apresentar aspecto mais avermelhado e, não raramente, sangramento espontâneo.

A lesão periférica de células gigantes (LPCG) e o fibroma ossificante periférico (FOP) foram considerados. A LPCG ocorre sobre a gengiva ou processo alveolar geralmente de mandíbula, com tendência a apresentar-se anterior à região de molares e predileção pelo gênero feminino. Sua etiopatogênese não foi totalmente esclarecida, porém se supóe que se origine do tecido conectivo da gengiva ou do processo alveolar, geralmente relacionado a fatores irritativos locais (Nogueira et al. ${ }^{9}$ 2004).

O FOP é mais comum entre a faixa etária de 20 a 40 anos, com predominância no gênero feminino. Essa lesão tem seu desenvolvimento normalmente em resposta a uma irritação crônica e, apesar da incerteza de sua patogênese, tem sido hodiernamente aceito que sua proliferação origina-se da membrana do periósteo ou perio- dontal. A localização mais frequente do FOP é a maxila, sendo a região anterior mais afetada. Apresenta maior incidência pela gengiva marginal e papila interdental. Dependendo do tempo de desenvolvimento, áreas de calcificaçóes no interior da lesão podem ser observadas no exame radiográfico, ajustando-se a exposição (Santiago et al. ${ }^{13}$ 2003).

Uma discussão muito frequente em relação à origem do FCG sugere que essa lesão tenha origem melanocítica devido à presença de melanina, a extensão dendrítica das células gigantes e a localização destas próxima ao epitélio de revestimento. Porém, o fato da reação negativa para S-100 desmente a possibilidade de origem no nervo periférico (Santiago et al. ${ }^{13}$ 2003).

O FCG deve ser identificado como uma entidade específica baseando-se nas suas características clínicas, distribuição anatômica, potencial de crescimento limitado e aspecto microscópico distinto, onde as células gigantes estreladas representam a sua principal característica.

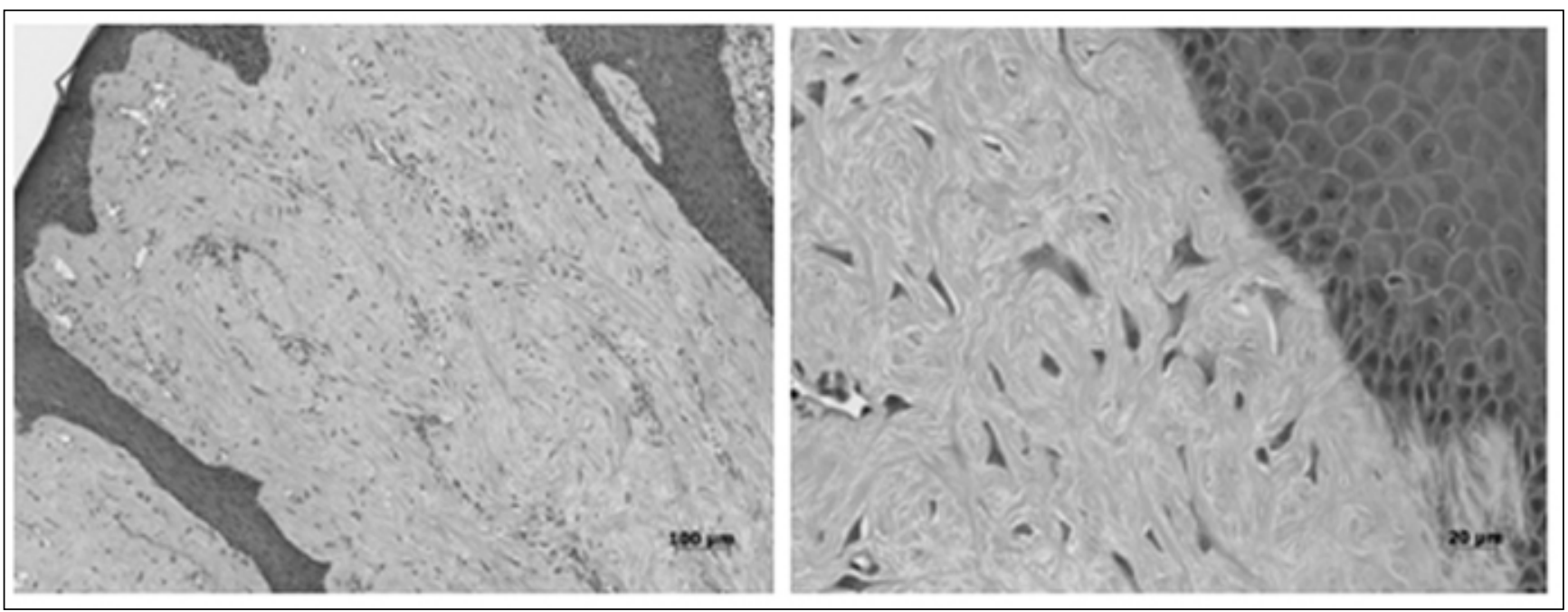

Figura 4 - Epitélio estratificado pavimentoso atrófico paraqueratinizado e tecido conjuntivo frouxo contendo numerosos fibroblastos grandes e estrelados, alguns deles multinucleados. 


\section{REFERÊNCIAS}

1. Albuquerque Jr RLC, Medeiros KBM, Pereira Pinto L, Souza LB. Fibroma de células gigantes: estudo histomorfológico de 21 casos e discussão dos conceitos atuais. Rev Bras Odontol 2001mar-abr; 58(2):122-8.

2. Araújo NS, Araújo VC. Neoplasias benignas e malignas. In: Araújo NS, Araújo VC. Patologia bucal. São Paulo: Artes Médicas; 1984. p. 117-41.

3. Campos E, Gomez RS. Immunohistochemical Study of Giant Cell Fibroma. Braz Dent J 1999; 10(2):8992.

4. Magnusson BC, Rasmusson LG. The giant cell fibroma: a review of 103 cases with immunohistochemical findings. Acta Odontol Scand 1995 Oct; 53(5): 293-6.

5. Miguel MCC, Andrade ESS, Rocha DAP, Freitas RA, Souza LB. Immunohistochemical expression of vimentin and HHF 35 in giant cell fibroma, fibrous hyperplasia and fibroma of the oral mucosa. $J A p p l$ Oral Sci 2003 Jan-Mar; 11(1): 77-82.

6. Mighell AJ, Robinson PA, Hume WJ. Immunolocalisation of tenascin- $C$ in focal reactive overgrowths of oral mucosa. J Oral Pathol Med 1996; 25: 163-9.

7. Mighell AJ, Robinson, PA, Hume WJ. PCNA and Ki-67 immunoreactivity in multinucleated cells of giant cell fibroma and peripheral giant cells granuloma. J Oral Pathol Med 1996; 25:193- 9.

8. Neville BW, Damm DD, Allen CM, Bouquot JE. Tumores dos tecidos moles. In: Neville BW, Damm DD, Allen CM, Bouquot JE. Patologia oral e maxilofacial. Rio de Janeiro: Guanabara Koogan; 1998. p.353-404.
9. Nogueira RLM, Cavalcante RB, Carvalho ACGS, Costa FWG. Lesão de células de gigantes: um estudo do diagnóstico diferencial em 04 casos clínicos. Rev Cir Traumatol Buco-Maxilo-Fac 2004 abr-jun; 4(2): 77-85.

10. Odell E, Lock C, Lombardi T. Phenotypic characterization of stellate and giant cells in giant cell fibroma by immunocytochemistry. J Oral Pathol Med 1994; 23(6): 284-7.

11. Pinto-Coelho CM, Silva-Sousa YTC, Daré AMZ, Cardoso CM. Avaliação preliminar das lesões da mucosa bucal associadas ao uso de prótese removível. Rev Odont Univ Ribeirão Preto 2000; 3:3-9.

12. Pinto-Coelho CM, Zucoloto, S. Hiperplasia fibroepitelial inflamatória da cavidade oral. Rev Assoc Paul Cir Dent 1998set-out; 52(5): 383-7.

13. Santiago LM, Gusmão ES, Silva UH. Fibroma ossificante periférico e hiperplasia fibrosa inflamatória relato de caso clínico. Odontol Clin Cient 2003set-dez; 2(3): $233-40$

14. Shafer WG, Hine MK, Levy BM. Tumores benignos e malignos da cavidade bucal. In: Shafer WG, Hine MK, Levy BM. Tratado de patologia bucal. 4 ed. Rio de Janeiro: Guanabara Kogan, 1987. p.80-212.

Recebido em: 1/9/2009

Aceito em: 1/10/2009 